\title{
Reducing the effect of proton pump inhibitors augmenting gastrointestinal sestamibi uptake
}

We thank Norouzi et $\mathrm{al}^{1}$ for a well-considered study of the topic of increased gastrointestinal sestamibi uptake due to proton pump inhibitor (PPI) medications. It is indeed a problem which confounds Nuclear Medicine specialists every day. It is important to overcome this as much as possible-and attenuation correction goes a long way toward this objective. Thus, Myocardial Perfusion Imaging (MPI) remains an integral part of the cardiac investigation process, especially for those with intermediate cardiovascular risk. ${ }^{2}$

By contrast to Norouzi et al ${ }^{1}$ who withheld PPIs, we thought about the counteracting effects of an additional aspirin to MPI patients. ${ }^{3}$ This was based on a hypothesized mechanism by which PPI-associated hypergastrinemia induces expression of cyclooxygenase 2 in the gastric mucosa promoting local synthesis of prostaglandins leading to hyperplasia and increased blood flow and thus increase MIBI uptake. We showed that clinically significant gastric wall uptake was more likely in those taking a PPI without aspirin (51\%) compared to those taking neither medication at baseline (13\%). We would like to study this further, prospectively.

It seems the latter would be much smoother from a medical/administrative point of view. Patients often have difficulty identifying which medication to stop, especially if all their assortments are pre-packaged by the pharmacy in a weekly supply/container. "Do you mean the little white one, doctor?" is the inevitable refrain. We cringe at those words. If this step can be bypassed, it would seem much more palatable.

Another population that would benefit are hospital inpatients that require the test on the same day or the next. The period required to withhold the PPI might be neither possible nor practical.

\author{
Joseph C. Lee, MBBS, FRACP, FAANMS, , $^{a, b}$ \\ David S. Rose, MBBS, FRACP, FAANMS ${ }^{a}$ \\ ${ }^{a}$ Department of Medical Imaging, The Prince Charles Hospital, \\ Chermside, $Q L D$ 4032, Australia \\ ${ }^{b}$ Faculty of Medicine, University of Queensland, Herston, Australia
}

\section{Acknowledgements}

None.

Author contributions Conception or design of the work; or the acquisition, analysis, or interpretation of data for the work: JCL $60 \%$ DSR $40 \%$. Drafting the work or revising it critically for important intellectual content: JCL 60\%, DSR $40 \%$

Disclosures $\mathrm{Dr}$ Lee has received travel expenses for attending meetings of his specialty College's Continuing Professional Development Committee, of which he is a member.

\section{References}

1. Norouzi G, AsadZade A, Salimi Y, Khoshbakht S, Pirayesh E. Effect of proton pump inhibitors and $\mathrm{H} 2$ antagonists on gastric wall uptake in myocardial perfusion scan with $99 \mathrm{mTc}$-sestamibi. J Nucl Cardiol 2021. https://doi.org/10.1007/s12350-021-02529-6.

2. Lee JC, West MJ, Khafagi FA. Myocardial perfusion scans. Aust Fam Physician 2013;42:564-7.

3. Rose DS, Robinson B, Kannan S, Lee JC. Interaction between the effects of proton pump inhibitors and aspirin on gastric wall sestamibi uptake on myocardial perfusion imaging. J Nucl Cardiol 2019. https://doi.org/10.1007/s12350-019-01951-1. doi:10.1007/s12350-021-02879-1

Publisher's Note Springer Nature remains neutral with regard to jurisdictional claims in published maps and institutional affiliations. 